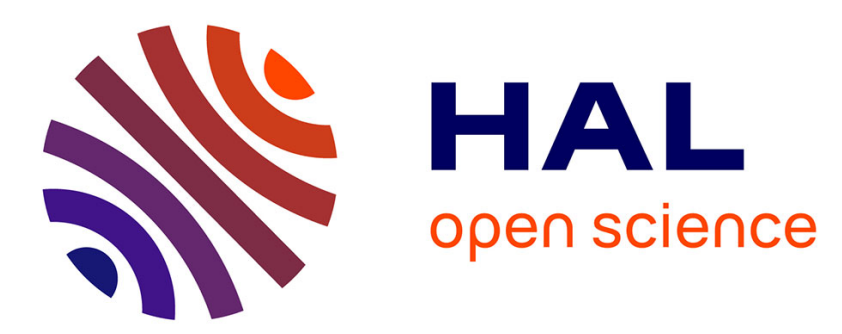

\title{
Compact Printed Quadrifilar Helix Antennas for Stratospheric Balloons Telemetry
}

Lamyaa Hanane, Sami Hebib, Hervé Aubert, Nelson Fonseca

\section{To cite this version:}

Lamyaa Hanane, Sami Hebib, Hervé Aubert, Nelson Fonseca. Compact Printed Quadrifilar Helix Antennas for Stratospheric Balloons Telemetry. Antennas and Propagation International Symposium, 2007 IEEE, Jun 2007, Honolulu, United States. pp. 1525 - 1528. hal-00432236

\section{HAL Id: hal-00432236 https://hal.science/hal-00432236}

Submitted on 15 Nov 2009

HAL is a multi-disciplinary open access archive for the deposit and dissemination of scientific research documents, whether they are published or not. The documents may come from teaching and research institutions in France or abroad, or from public or private research centers.
L'archive ouverte pluridisciplinaire HAL, est destinée au dépôt et à la diffusion de documents scientifiques de niveau recherche, publiés ou non, émanant des établissements d'enseignement et de recherche français ou étrangers, des laboratoires publics ou privés. 


\title{
Compact Printed Quadrifilar Helix Antennas for Stratospheric Balloons Telemetry
}

\author{
L. Hanane* ${ }^{(1,2)}$, S. Hebib ${ }^{(1,3)}$, H. Aubert ${ }^{(1,2)}$ and N. Fonseca ${ }^{(4)}$
}

(1) LAAS-CNRS, 7 avenue du Colonel Roche, 31077 Toulouse, FRANCE

(2) INPT-ENSEEIHT, 2 rue Charles Camichel, 31071 Toulouse, FRANCE

(3) AD2M-UPS, 118 Route de Narbonne, 31062 Toulouse, FRANCE

(4) CNES, 18 avenue Edouard Belin, 31401 Toulouse, FRANCE

\section{Introduction}

Printed Quadrifilar Helices (PQH) antennas have found application in L-band telemetry for meteorological stratospheric balloons. The PQH antenna, patented by the CNES [1], is relatively simple to manufacture and low cost. Such an antenna has good circular polarization coverage with excellent axial ratio over a wide range of elevation angle. However the reduction in size of modern stratospheric balloon payloads asks for more compact $\mathrm{PQH}$ antennas.

Consequently, the challenging problem consists of reducing the axial length of conventional $\mathrm{PQH}$ antennas with a minimum impact upon their overall performances. In the literature, meander lines [2, 3] and pre-fractal (space-filling) curves [4] were applied to the arms of helix antennas in order to reduce its length. Compact PQH antennas with meander lines have been reported in [3] but the performances of the proposed antennas in term of the axial ratio (which are of crucial importance in our application) are not compared with those of conventional PQH antennas. In [4] pre-fractal curves have been used to reduce the axial length of monofilar helices antennas but, from a practical point of view, the extension to quadrifilar helices appears to be highly problematic.

In this communication, the four arms of quadrifilar helices antennas are prefractal and printed on the cylindrical surface of the antenna. Very few of such prefractal $\mathrm{PQH}$ antennas are found to achieve the technical requirements for L-band stratospheric balloons telemetry. We present in this paper a solution with a 33\% axial length reduction when compared to the original $\mathrm{PQH}$ antenna. The obtained axial ratio is lower than $2 \mathrm{~dB}$ for elevation angle between $-80^{\circ}$ and $80^{\circ}$.

\section{Design of pre-fractal Printed Quadrifilar Helixes antennas}

Based on the Iteration Function System (IFS) algorithm [5], a specific software has been developed to generate the pre-fractal profile of PQH antennas. The total length of such profiles is adjusted in order to obtain the same operating frequency $(1.85 \mathrm{GHz})$ for each studied $\mathrm{PQH}$ antenna and to achieve the technical requirements in terms of radiation pattern (radial mode) and input impedance (close to $50 \Omega$ ). The axial ratio is required to be lower than $2 \mathrm{~dB}$ over elevation 
angle range as large as possible. In order to achieve circular polarization, the four arms of the $\mathrm{PQH}$ antennas are excited with the following classical phase law: $0^{\circ}$, $90^{\circ}, 180^{\circ}$ and $270^{\circ}$.

The pre-fractal profiles with interesting characteristics are shown in Figure 1. These profiles are printed on a thin low-permittivity dielectric substrate (Figure 2) and wrapped around a cylindrical support. The Figure 3 shows the resulting PQH antennas. The design and the simulation of these antennas are performed using IE3D software based on the Method of Moments.

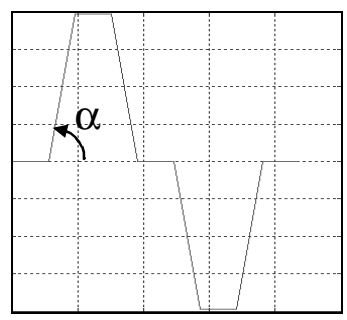

(a)

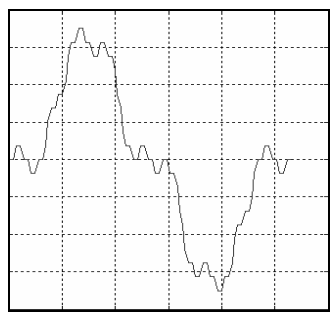

(b)

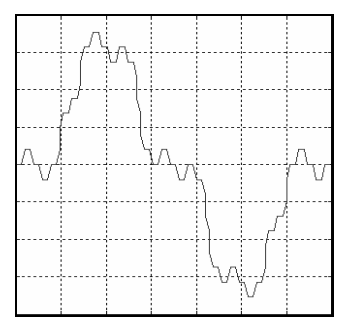

(c)

Figure 1. Pre-fractal profiles: (a) at the first-order iteration; (b) at the second-order iteration with $\alpha=30^{\circ}$ and (c) at the second-order iteration with $\alpha=45^{\circ}$.

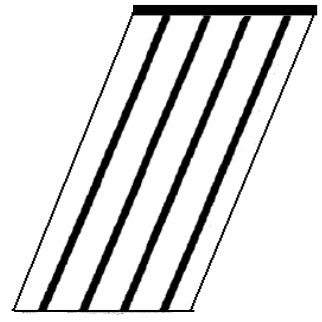

(a)

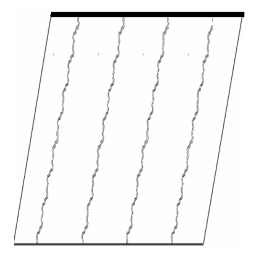

(b)

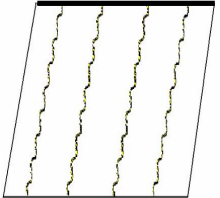

(c)

Figure 2. Planar representations of: (a) the conventional $\mathrm{PQH}$ antenna;

(b) the pre-fractal "PQH-F1" antenna with the profile shown in Fig.1b and

(c) the pre-fractal "PQH-F2" antenna with the profile shown in Fig.1c.

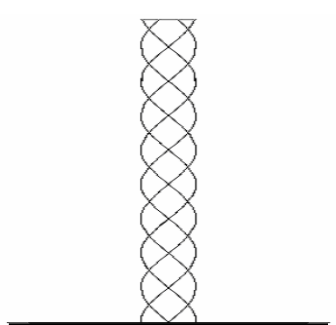

(a)

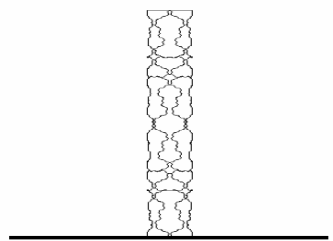

(b)

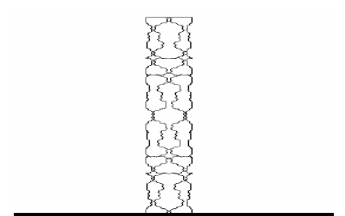

(c)

Figure 3. Three Printed Quadrifilar Helix having the same operating frequency:

(a) the conventional $\mathrm{PQH}$ antenna; (b) the PQH-F1 antenna and

(c) the PQH-F2 antenna 
The PQH-F1 and PQH-F2 antennas reduce the axial length of the conventional $\mathrm{PQH}$ antenna by $33 \%$ and $38 \%$, respectively. The Figure 4 displays the simulated LHCP and RHCP directivity patterns of these two compact antennas at the desired operating frequency. In term of the LHCP gain pattern, these two antennas will be slightly out of the requirements in some radiating directions (the desired minimal LHCP gain patterns are displayed in the figure). However, the axial ratio of the $\mathrm{PQH}-\mathrm{F} 1$ antenna is lower than $2 \mathrm{~dB}$ for elevation angle between $-70^{\circ}$ and $70^{\circ}$. Moreover, with printed line widths of $1 \mathrm{~mm}$, the input reflection coefficient is found to be close to $-16 \mathrm{~dB}$ for the PQH-F1 antenna while this coefficient is close to $-22.5 \mathrm{~dB}$ in the case of the PQH-F2 antenna with line widths of $0.8 \mathrm{~mm}$.

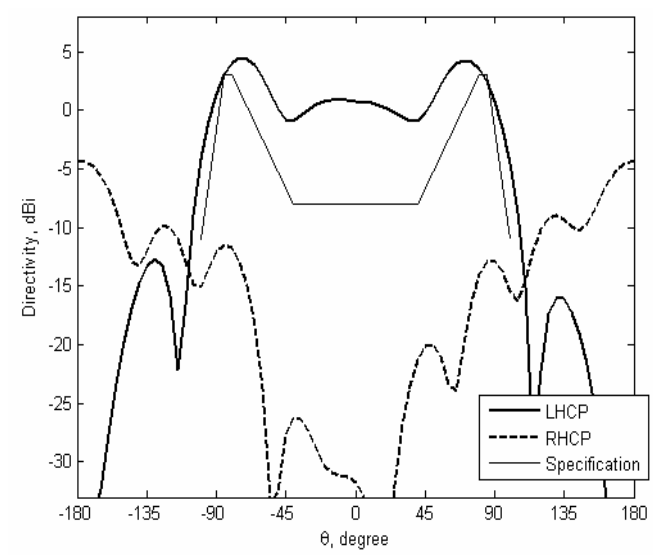

(a)

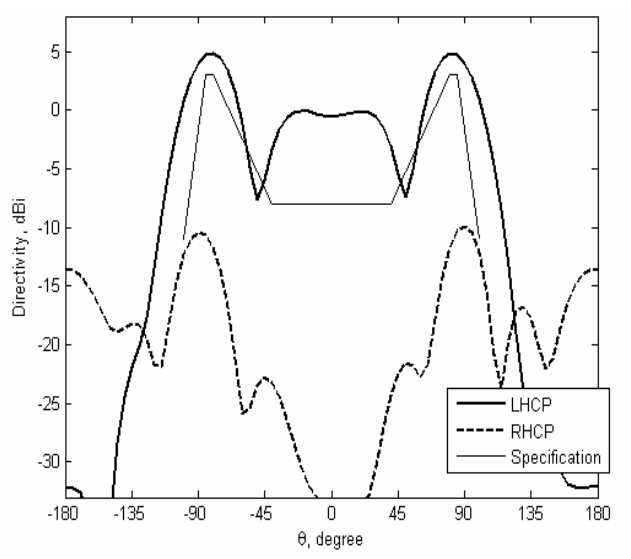

(b)

Figure 4. The simulated radiation patterns for :

(a) the PQH-F1 antenna and (b) the PQH-F2 antenna.

Table 1 summarizes the characteristics of the PQH, PQH-F1 and PQH-F2 antennas.

\begin{tabular}{|c|c|c|c|}
\cline { 2 - 4 } \multicolumn{1}{c|}{} & $\begin{array}{c}\text { Conventional } \\
\text { PQH }\end{array}$ & PQH-F1 & PQH-F2 \\
\hline Antenna axial height & $340 \mathrm{~mm}$ & $227 \mathrm{~mm}$ & $211 \mathrm{~mm}$ \\
\hline Total wire length & $380 \mathrm{~mm}$ & $322 \mathrm{~mm}$ & $341 \mathrm{~mm}$ \\
\hline Operating frequency & $1.85 \mathrm{GHz}$ & $1.85 \mathrm{GHz}$ & $1.85 \mathrm{GHz}$ \\
\hline Size reduction & $0 \%$ & $33 \%$ & $38 \%$ \\
\hline Input reflection coefficient & $-25 \mathrm{~dB}$ & $-16 \mathrm{~dB}$ & $-22.5 \mathrm{~dB}$ \\
\hline width of the printed lines & $5.5 \mathrm{~mm}$ & $1 \mathrm{~mm}$ & $0.8 \mathrm{~mm}$ \\
\hline
\end{tabular}

Table 1. Characteristics of the PQH, the PQH-F1 and PQH-F2 antennas.

Very few pre-fractal PQH antennas are found to achieve the technical requirements for L-band stratospheric balloons telemetry, especially in term of 
co-polarized field. In the generation of the pre-fractal profile, as the order of iteration increases in the IFS algorithm, the resulting pre-fractal PQH antenna seems to enhance the axial mode to the detriment of the desired radial mode of radiation. Moreover, according to the electromagnetic simulations, we have observed that classical sinus-type profiles offer analogous performances to prefractal PQH-F1 and PQH-F2 antennas in terms of directivity patterns and size reduction.

\section{Conclusion}

Two pre-fractal Printed Quadrifilar Helices antennas have been presented. These compact antennas offer good compromises between size and performances. The designs introduced in this paper reveal the feasibility of an axial length reduction between 30 to $40 \%$ without significant cross-polarization degradation. Experimental validations will be presented at the conference.

\section{Acknowledgement}

The authors would like to thank Errazi Rachid for his helpful development of the IFS-based software for the generation of the pre-fractal profiles.

\section{References:}

[1] A. AURIOL, "Helix-type antenna and its manufacturing process," European Patent, publication number: 0320404A1, 14 Juin 1989.

[2] D. K. C. CHEW, S. R. SAUNDERS, "Meander line technique for size reduction of quadrifilar helix antenna," IEEE Antennas and wireless propagation letters, vol. 1, no. 1, pp. 109-111, 2002.

[3] Y. LETESTU, A. SHARAIHA, P. BESNIER, "A size reduced configurations of printed quadrifilar helix antenna," Antenna Technology: Small Antennas and Novel Metamaterials, IWAT 2005, IEEE International Workshop on, pp. 326 - 328, 7-9 March 2005.

[4] N. COHEN, "NEC 4 analysis of a fractalized monofilar helix in an axial mode," Conference proceedings, 14th Annual review of progress in Applied Computational Electromagnetics at the Naval Postgraduate School Monterey, CA, vol. 2, March 16-20, 1998.

[5] H. JURGENS, H. O. PEITGEN, D. SAUPE, "Chaos and Fractals: New Frontiers of Science," Springer-Verlag, New York, 1992. 